\title{
NEW SPECIES AND GENERA OF AMISEGINAE FROM ASIA (CHRYSIDIDAE, HYMENOPTERA)*
}

\author{
BY LYNN SIRI KIMSEY \\ Department of Entomology, \\ University of California, Davis 95616
}

In a large shipment of miscellaneous, non-American chrysidids sent to me by Henry Townes of the American Entomological Institute, Gainesville, Florida, all of the Amiseginae turned out to be new species. The majority of these were collected by $\mathrm{E}$. and $\mathrm{M}$. Becker in the Pasoh Forest Reserve in Malaysia. The new species of Cladobethylus and Isegama represent range extensions for both genera. Cladobethylus was previously known from Sri Lanka and Mindanao, Philippines. Isegama has been previously described only from Sri Lanka.

Holotypes have been deposited in the American Entomological Institute, Gainesville, Florida.

A variety of structures, dimensions and abbreviations, used below, need explanation. The malar space is the distance between the base of the mandible and the ocular margin. On the mesopleuron there are 2 possible carinae and/or sulci. The scrobal sulcus extends transversely across the mesopleuron from the scrobal pit. The oblique mesopleural carina originates below the pronotal lobe, and extends ventrally. Subantennal distance is the length between a line drawn across the lower edge of the antennal sockets and the clypeal apex. Abbreviations used below are: $\mathrm{F}=$ flagellum, $\mathrm{MOD}=$ midocellus diameter, $\mathrm{PD}=$ puncture diameter and $\mathrm{T}=$ gastral tergum.

Atoposega simulans Kimsey, new species

(Figs. 1, 6)

Holotype female. Body length $5 \mathrm{~mm}$. Face (fig. 1); scapal basin with numerous coarse cross-ridges, bordered along ocular margin by large punctures less than 0.6 PD apart; malar space 3 MOD;

*Manuscript received by the editor April 4, 1986. 
head width 1.3 times length; midocellus 2.5 MOD from ocular margin; subantennal distance $1 \mathrm{MOD}$; ocelli arranged in broad triangle; hindocellus 1.2 diameters from ocular margin; F-I length $3 X$ breadth; F-II length $0.6 \times$ breadth; pronotum $0.5 \times$ as long as combined median lengths of scutum, scutellum and metanotum; mesopleuron with large dense punctures, without scrobal sulcus; scutal punctures coarse and contiguous, somewhat arranged in rows; metanotum $0.8 \times$ scutellar length; forewing (fig. 6) densely setose with dark bands across wing at medial vein and at apex of RS (fig. 6), entire wing brown-stained; hindfemur ventral surface coarsely punctate; T-I and II polished and impunctate medially with lateral zone of fine scratches and punctures; T-III-IV with apical band of tiny punctures. Head black; scape light brown; pedicel and F-I whitish, except apex of F-I blackish; F-II-XI blackish; thorax red, except dorsal and posterior face of propodeum black; legs and coxae red, except foretarsomeres, hindtibial apex and venter of hindfemur dark brown; abdomen shiny black, with faint green tints on T-I-II laterally.

Holotype female: MALAYSIA: Pasoh Forest Res., Negri S., 17 April 1980, P. and M. Becker (GAinesville). Paratypes: 10 females, same data as type, except various dates from 8 July 1978 to 3 November 1979.

Discussion. This species appears to be structurally intermediate between the other species of Atoposega: lineata Krombein and rieki (Krombein). A. simulans has the long pronotum, patterned wings and larger size of lineata, and T-I-II laterally "scratched" with metallic tints and the forefemur rough and coarsely punctate, as in rieki.

\section{Bupon Kimsey, new genus}

Diagnosis. Malar space with vertical sulcus; vertex with coarse close punctation; brow with strongly projecting transverse ridge (figs. 3,4 ); eyes encircled by irregular carina; occipital carina welldeveloped; scapal basin coarsely cross-ridged; male flagellum short and cylindrical; pronotum about half as long as combined lengths of scutum, scutellum and metanotum, with oblong pit posteromedially and on lateral lobe; mesopleuron without scrobal sulcus or oblique 


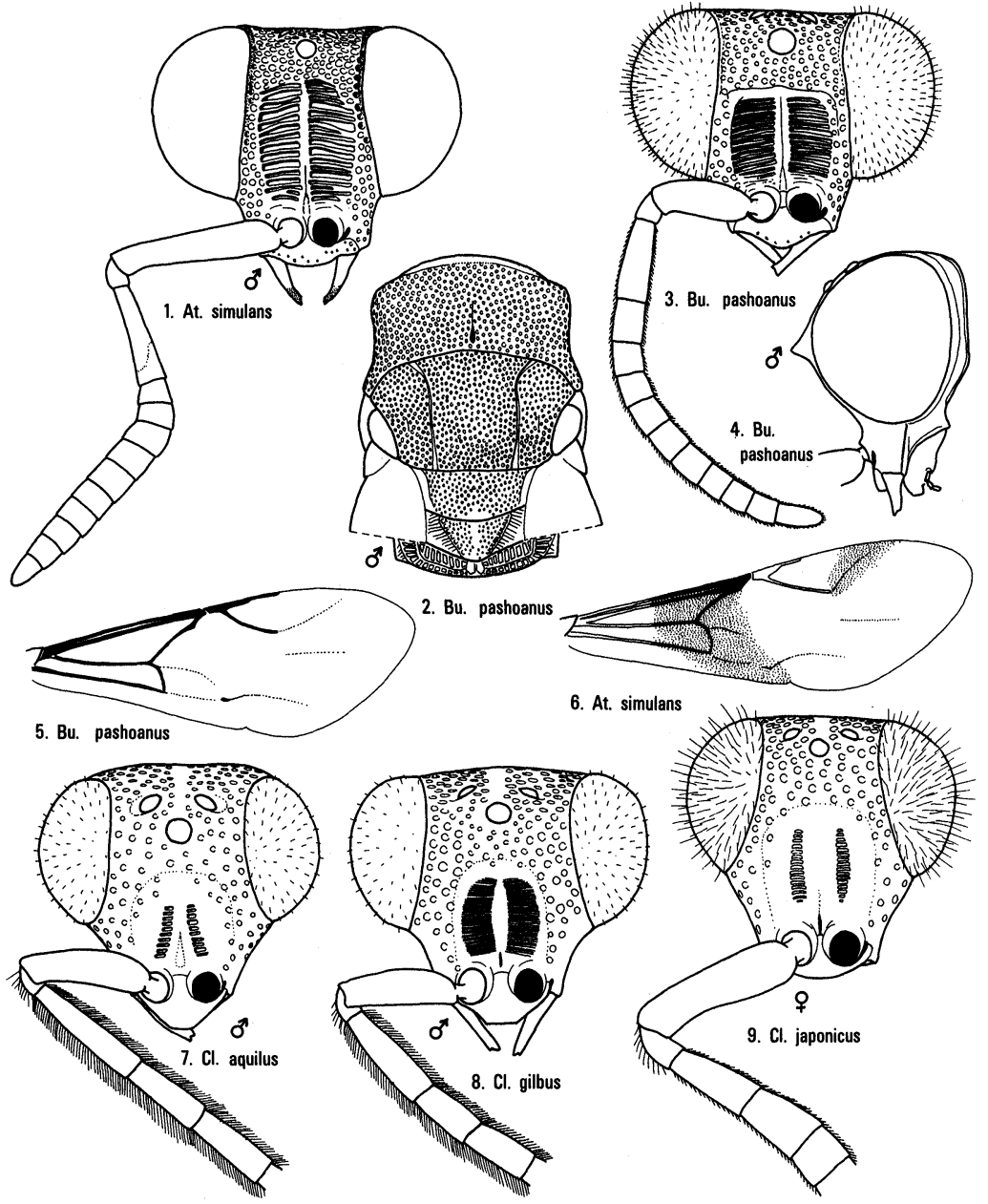

Figs. 1, 3, 7-9. Front view of face. Fig. 2. Dorsal view of thorax. Fig. 4. Lateral view of head. Figs. 5, 6. Forewing. 
mesopleural carina; forewing (fig. 5) with long slender stigma + R1, RS extended by evenly curved streak, medial vein arises before cu-a; metanotum $0.9 \times$ as long as scutellum, medial enclosure punctate, differently sculptured from lateral area; propodeum with short dorsal surface, abruptly declivous posteriorly, lateral angles short and blunt; hindcoxa with dorsobasal carina; terga sharp-edged laterally, covered with dense small punctures; tarsal claw with large perpendicular submedial tooth.

Type: Bupon pasohanus Kimsey.

Etymology. $\quad B u$ - great, pons - bridge (Latin, masculine).

Discussion. The most unusual diagnostic feature of Bupon is the strongly projecting transverse frontal carina. The only other amisegine genus with any indication of such a carina is Perissosega where it is faint by comparison. In other respects Bupon more closely resembles Cladobethylus, based on the lack of most of the derived characteristics found in the Amiseginae. Two derived characteristics that are found in Bupon and will immediately distinguish this group are the transverse facial carina and the short, relatively broad male flagellum.

\section{Bupon pasohanus Kimsey new species}

(Figs. 2-5)

Holotype male. Body length $4.5 \mathrm{~mm}$. Face (figs. 3, 4); scapal basin with coarse cross-ridges, deeply sunken below transverse shelf-like ridge, punctures $0.2-0.5 \mathrm{PD}$ apart; eye encircled by carina; clypeal apex broadly rounded; subantennal distance 1 MOD; malar space 2.1 MOD, with vertical sulcus; ocelli arranged in broad triangle; hindocelli 0.8 diameter from ocular margin; midocellus 1.8 MOD from ocular margin; occipital carina complete; pronotum $0.5 \times$ combined lengths of scutum, scutellum and metanotum; with oblong pit posteromedially and on lateral lobe; thorax (fig. 2), with dorsal punctures coarse and contiguous; mesopleuron sculptured like pronotum, without scrobal sulcus; propodeal posterior face finely and densely rugose, lateral angle short and blunt; terga sharpedged laterally, with coarse small punctures 0.5 PD apart. Body black; legs including coxae yellow, except hindtarsomeres and apices of hindfemur and tibia blackish; antenna dark brown, except scape paler beneath. 
Holotype male: MALAYSIA: Pasoh Forest Res., Negri S., E. and M. Becker, 27 July 1979, secondary forest (GAINESvilLE). Paratypes: 30 males, collected from June 1978 to April 1980.

Cladobethylus aquilus Kimsey, new species

(Fig. 7)

Holotype male. Body length $3 \mathrm{~mm}$. Face (fig. 7); scapal basin primarily smooth with short strip of cross-ridges on either side of broad medial stripe; clypeus long and rounded apically, subantennal distance 1.1 MOD; malar space 3.5 MOD long; head about as long as wide; midocellus 2 MOD from ocular margin; ocelli arranged in nearly equilateral triangle; hindocelli separated from ocular margin by 0.8 diameters; pronotum about $1.2 \times$ as long as scutum; mesopleuron with long parallel-sided scrobal sulcus, punctures slightly larger than on pronotum; metapleuron smooth below hindwing base; propodeum with posteromedial stripe smooth but somewhat irregular, bordered by carina laterally; terga with basal zone of tiny punctures 0.5-2 PD apart. Body black, except pronotum and scutum with faint blue tint; legs including coxae yellow; antennae dark brown; mandibles yellowish brown.

Female unknown.

Holotype male: PAPUA NEW GUINEA: Bulolo, $900 \mathrm{~m}, 13$ February-13 March 1979, J. Sedlacek (GAINESviLle). Paratypes: 4 males, same data as type, 1 male Baiyer River, 6-25 February 1979, $1100 \mathrm{~m}$.

Discussion. The face of aquilus resembles that of C. ceylonicus Krombein based on the strongly converging lower sides of the face and the greatly reduced cross-ridging in the scapal basin. However, aquilus can be distinguished from this and other Cladobethylus species by the long clypeus, smooth metapleuron, dorsum with faint blue tints, dark brown antenna, and pronotum longer than the scutum.

\section{Cladobethylus gilbus Kimsey, new species}

(Fig. 8)

Holotype male. Body length $4 \mathrm{~mm}$. Face (fig. 8); scapal basin with numerous fine cross-ridges, bordered by large punctures less than 0.6 PD apart; head venter with 2 ovoid foveae along midline of genal 
bridge; malar space 3.2 MOD long; head $1.2 \times$ as wide as long; midocellus 2.5 MOD from ocular margin; ocelli arranged in a nearly equilateral triangle; hindocelli separated from ocular margin by 1 diameter; subantennal distance 0.9 MOD; clypeal apex truncate; pronotum with fine short posteromedial line; mesopleuron without scrobal sulcus, punctation same as pronotum; metapleuron with zone of cross-ridging below hindwing base; propodeum with broad, polished, impunctate, vaguely margined, posteromedial stripe; terga polished and impunctate. Body black, except pronotum and scutum with faint blue tints; antennae, legs including coxae yellow, and mandibles yellow with red tips.

Female unknown.

Holotype male: MALAYSIA: Pasoh Forest Res., Negri S., 5 November 1978. P. and M. Becker (GAINESVILLE). Paratypes: 106 males and 50 females, same data as type, except dates from May 1978 to May 1980.

Discussion. C. gilbus males have two ovoid foveae underneath the head, one on either side of the genal bridge. I have seen no other Cladobethylus males with this modification. Otherwise, gilbus can be distinguished by the densely cross-ridged scapal basin, yellow antennae, truncate, clypeal apex, subequal pronotum and scutum (in length), blue-tinted pronotum and scutum and metapleuron with short zone of cross-ridging.

\section{Cladobethylus japonicus Kimsey, new species}

(Fig. 9)

Holotype female. Body length $2.5 \mathrm{~mm}$; face (fig. 9); scapal basin smooth with short strip of cross-ridges on either side of broad medial stripe; clypeus short, broadly rounded; subantennal distance 0.6 MOD; malar space $5 \mathrm{MOD}$ long; face broad across genal region, about as broad as long; midocellus 2.6 MOD from ocular margin; ocelli arranged in nearly equilateral triangle; hindocelli separated from ocular margin by 0.3 diameters; mesopleuron with long parallel-sided scrobal sulcus, punctures larger than on pronotum; metapleuron cross-ridged from hindwing base nearly to midcoxa; propodeum posteromedial stripe rough and enclosed by strong carina; T-I smooth and impunctate; T-II-IV smooth with tiny scattered punctures 4-6 PD apart. Body black with bluish tints on vertex and 
pronotum; legs including coxae yellow; scape dark brown becoming paler distally; pedicel and F-I-III yellow, remaining flagellomeres brown; mandibles brown.

Male unknown.

Holotype female: JAPAN: Kyoto, 8 August 1980, H. and M. Townes (GAINESVILlE).

Discussion. This species has several unusual features. The eyes have very long dense setulae, the hindocelli are very close to the ocular margins and the malar space is also very long. In addition, the lower face is quite broad, the scapal basin has only narrow stripes of cross-ridging, the pronotum is longer than the scutum, the metapleuron is cross-ridged from wing base to caxa, and only the pedicel and F-I-III are yellow, the rest of the antenna is brown.

\section{Isegama malaysiana Kimsey, new species}

(Fig. 17)

Holotype female. Body length $3 \mathrm{~mm}$. Face (fig. 17) polished with sparse small punctures, 3-5 PD apart; eyes without distinct setulae; scapal basin shallow with faint cross-ridges; lower face strongly converging; eyes bulging farthest below middle; gena bulging along lower third of eye; malar space 3.2 MOD long; clypeus short, subantennal distance 0.4 MOD; midocellus 2 MOD from ocular margin; ocelli arranged in broad triangle; hindocellus nearly touching ocular margin; vertex strongly convex; pronotum flattened, with medial groove and pit before lateral lobe, subequal to scutal length; mesopleuron with moderate punctures about $1 \mathrm{PD}$ apart on anterior half, posterior half impunctate and polished, scrobal sulcus straight, narrow and parallel-sided, oblique mesopleural carina well-developed; metanotum $0.8 \times$ scutellar length, medial enclosure smooth with tiny punctures, about 1 PD apart; propodeum with dorsal enclosures polished and impunctate, posterior face rugose; T-I-III covered with close small punctures, nearly contiguous anteriorly but becoming more dispersed posteriorly, with impunctate medial stripe; T-IV covered with small punctures. Head, thorax and abdomen black, with blue tints on head, pronotum, scutum, scutellum and medial enclosure of metanotum; scape, pedicel and F-I-III yellow, F-IV to apex brown; legs including coxae yellow, wings faintly brown tinted. 
Male. Same as female except face more coarsely punctate, punctures 0.5-1.0 PD apart, eyes normal; F-I $3 \times$ as long as broad; terga more closely and coarsely punctate, without clearly indicated impunctate medial stripe; head and thorax without metallic tints; entire antennae reddish brown; femora dark brown becoming paler distally; coxae black.

Holotype female. MALAYSIA: Pasoh Forest Res., Negri S., 11 August 1979, forest gap, P. and M. Becker (GAINESVILLE). Paratype male, same data as type, except 29 February 1979.

Discussion. The face of malaysiana most closely resembles that of meaculpa Krombein due to the bulging eyes and strongly converging lower face. However, it differs significantly from meaculpa and aridula Krombein based on characteristics of the female, including the head only slightly wider than long, the scape, pedicel, F-I-II, and the legs entirely yellow, and in both sexes the thoracic dorsum with punctures relatively shallow and well-separated, the pronotum and scutum subequal in length, and the metanotum and propodeum without rugulae between the major ribbing.

\section{Kryptosega Kimsey, new genus}

Diagnosis. Malar space with vertical sulcus; occipital carina well-developed, at least dorsally; scapal basin shallow, with some cross-ridging; male flagellum elongate and cylindrical; pronotum with shallow, occasionally faint, posteromedial groove and pit before lateral lobe, $0.8-0.9 \times$ scutal length (fig. 11); mesopleuron with scrobal sulcus indicated by broad dorsally carinate groove or nearly absent, without oblique mesopleural carina; scutum with notauli deep posteriorly and obsolescent anteriorly, parapsides present; metanotum with poorly defined, punctate medial area, $0.8 \times$ as long as scutellum; propodeum rounded laterally and posteriorly, with relatively long dorsal surface; hindcoxa without dorsobasal carina; tarsal claw with large medial tooth; male fully winged, forewing (fig. 19), stigma broad and elongate, without indication of R1, RS extended by evenly curved dark streak, medial vein arising before cu-a; terga sharp-edged laterally and finely punctate.

Female unknown.

Type: Kryptosega anomala Kimsey.

Etymology: Krypto-hidden, sega - taken from Amisega Cameron. 


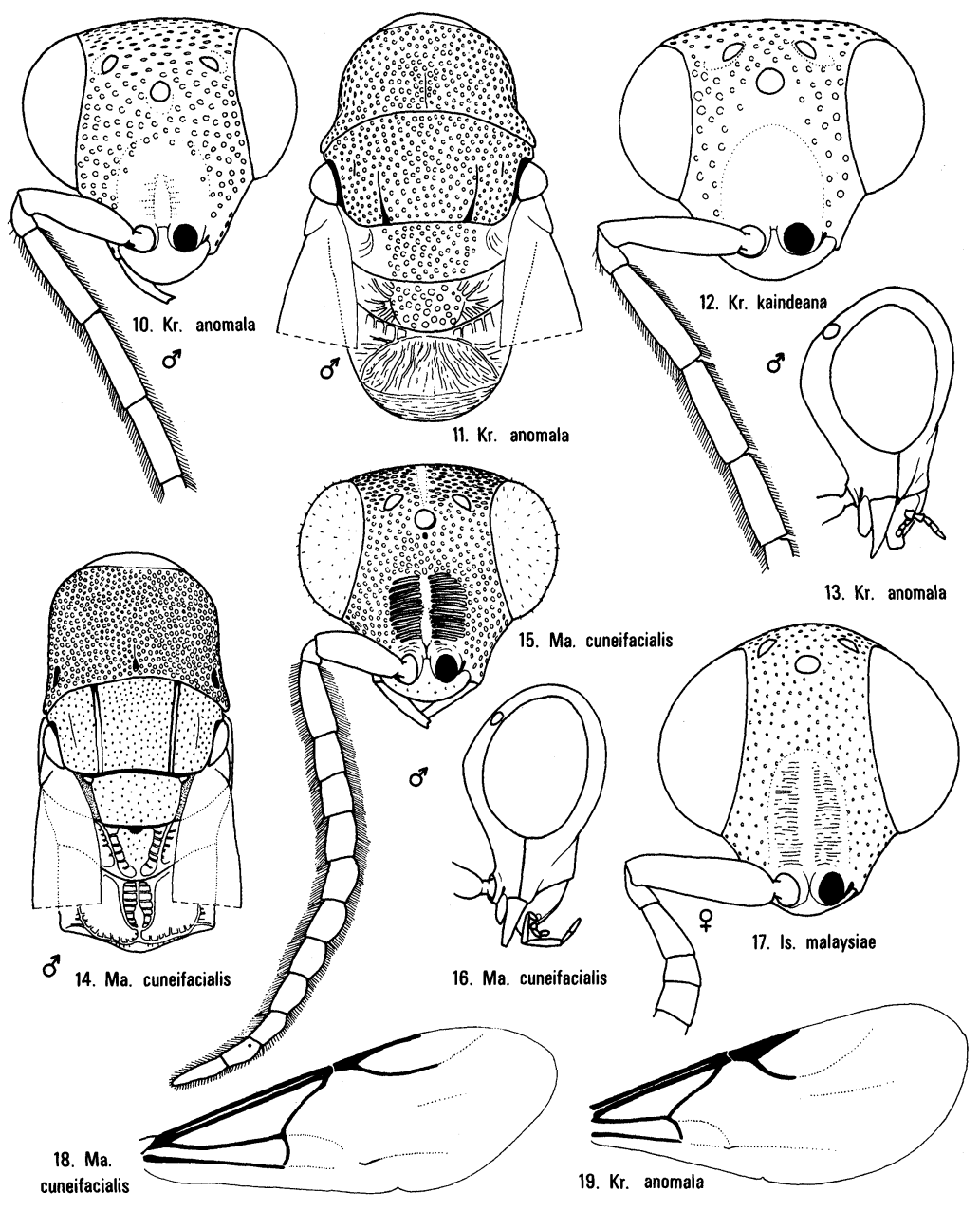

Figs. 10, 12, 15, 17. Front view of face. Figs. 13, 16. Lateral view of head. Figs. 11, 14. Dorsal view of thorax. Figs. 18, 19. Forewing. 
Discussion. This genus does not appear to be closely related to any of the other Amiseginae. Kryptosega lacks most of the derived characteristics found in other genera, except that it has no hindcoxal carina and no indication of a lateral propodeal angle. Further study is necessary to determine the relationships of Kryptosega.

Kryptosega anomala Kimsey, new species

(Figs. 10, 11, 13, 19)

Holotype male. Body length $3 \mathrm{~mm}$. Face (figs. 10, 13); scapal basin flattened and impunctate; frons with punctures 0.5-1.0 PD apart; malar space 4.4 MOD; head about as long as wide; midocellus 3.6 MOD from ocular margin; ocelli arranged in broad triangle; hindocellus separated from ocular margin by 0.3 diameter; clypeus long and rounded apically; subantennal distance 1.8 MOD; F-I length $4.3 \times$ breadth; F-II $3.6 \times$ as long as broad; pronotal, scutal and scutellar punctures 0.2-0.5 PD apart; pronotum and scutum subequal in length; scutum with notauli absent anteriorly; mesopleuron with broad irregularly margined depression extending from near pronotal lobe to scrobe, punctures 0.2-1.0 PD apart; metanotum $0.8 \times$ as long as scutellum, medial enclosure with large nearly contiguous punctures; propodeal dorsal surface with irregular longitudinal carinae, posterior surface with extensive transverse carinae; terga with sparse small punctures 2-3 PD apart. Head and thorax black without metallic tints; abdomen black, except reddish brown basally; scape and pedicel brown; flagellum black; coxae whitish, legs otherwise pale brown becoming darker on tarsi; mandibles yellowish becoming red apically.

Holotype male - NEW GUINEA: Mt. Kainde, 13 February-12 March 1979, 2300 m, J. Sedlacek (GAINESVILLE). Paratypes: 5 males, same data as type except also collected 18 January-14 February 1979 and 19 December 1978-8 January 1979.

Discussion. K. anomala can be distinguished from kaindeana by the coarser punctation, longer malar space and subantennal distance, and nonmetallic color.

Kryptosega kaindeana Kimsey, new species (Fig. 12)

Holotype male. Body length $2.5 \mathrm{~mm}$. Face (fig. 12); scapal basin impunctate and highly polished; frons with punctures shallow, 
0.5-1.0 PD apart; malar space 2.3 MOD; midocellus 2.6 MOD from ocular margin; ocelli arranged in nearly equilateral triangle; hindocellus 1 diameter from ocular margin; head $1.2 \times$ as wide as long; clypeus short, broadly rounded; subantennal distance 0.9 MOD; F-I length $4.3 \times$ breadth; F-II $3.5 \times$ as long as broad; pronotal, scutal and scutellar punctures shallow and 0.5-1.0 PD apart; pronotum $0.8 \times$ scutal length; scutum with notauli complete; mesopleuron with short depression near pronotal lobe, broadly separated from scrobe, punctures large, 0.5-1 PD apart; metanotum 0.9 $\times$ as long as scutellum, medial enclosure punctures shallow and nearly contiguous; propodeum strongly bulging posteromedially, dorsal surface irregularly rugose, posterior surface smooth; terga with sparse tiny punctures 2-4 PD apart. Head and thorax black with bronze tints dorsally; abdomen black, except reddish brown basally and faint bluish tints dorsally; antenna dark brown; mandibles whitish basally, red apically; coxae whitish, legs otherwise pale brown except hindtibial apex and tarsomeres dark brown.

Holotype male - NEW GUINEA: Mt. Kainde, 19 December 1978-18 January 1979, 2300 m, J. Sedlacek (GAINESVILLE). One paratype male same data as type, except 18 January-14 February 1979.

Discussion. Unlike anomala, kaindeana is bronze colored dorsally. In addition, the integument appears glossy and is less coarsely punctate and the face, particularly the malar space and subantennal distance, are shorter.

\section{Magdalium Kimsey, new genus}

Diagnosis. Malar space with vertical sulcus; vertex with impunctate medial stripe extending from midocellus to occiput; occipital carina absent; scapal basin shallow, coarsely cross-ridged; male flagellum broad, F-V-XI bulging medially (fig. 15); female flagellum short and broad, flattened on one side; pronotum long and flat, with oblong pits posteromedially and on lateral lobe, $0.6 \times$ combined lengths of scutum, scutellum and metanotum (fig. 14); mesopleuron with short oblique mesopleural carina, and scrobal sulcus long and parallel-sided; scutum with notauli deep and straight, parapsides faint; metanotum as long as scutellum, medial enclosure differently sculptured than laterally; propodeum with long dorsal surface and abruptly declivous posterior, lateral angles short and blunt; hindcoxa with dorsobasal carina; tarsal claw with large perpendicular, 
medial tooth; male forewing (fig. 18), stigma long and slender, R1 not indicated, RS extended by evenly curved streak, medial vein arising at cu-a; terga sharp-edged laterally, densely punctate except T-I-II with impunctate medial welt.

Type: Magdalium cuneifacialis Kimsey.

Etymology: Magdalium = cylindrical figure (Latin, neuter)

Discussion. These are relatively large amisegines, which most closely resemble Isegama, based on having a scrobal sulcus and oblique mesopleural carina, short broad male flagellomeres and the forewing medial vein arising at cu-a. However, Magdalium can be distinguished by the odd lobular male flagellomeres, long flattened pronotum, the absence of a well-defined occipital carina and the long compressed body shape. Also, Magdalium has an impunctate stripe on the vertex extending between the midocellus and the occiput much as in Cladobethylus.

\section{Magdalium cuneifacialis Kimsey, new species}

(Figs. 14-16, 18)

Holotype male. Body length $5 \mathrm{~mm}$. Face (figs. 15, 16); scapal basin with polished medial stripe and coarse cross-ridges laterally, punctures about 1 PD apart; malar space 4 MOD long, with vertical sulcus; head as wide as long; occipital carina present dorsally; midocellus 2.5 MOD from ocular margin; ocelli arranged in broad triangle; vertex with impunctate medial stripe from midocellus to occiput; hindocellus 1 diameter from ocular margin; pronotum long and flat, $0.6 \times$ combined lengths of scutum, scutellum and metanotum along midline, with large pit posteromedially and on lateral lobe; mesopleuron with subalar fossa, short oblique mesopleural carina and scrobal sulcus long and parallel-sided; notal punctures 0.2-0.5 PD, larger on head and pronotum than scutum; scutum with notauli deep and straight; metanotum $0.9 \times$ as long as scutellum; propodeum with short blunt lateral angles; T-I-II punctures dense and nearly contiguous, except impunctate medial welt; T-III-V with posterior band of punctures. Head, thorax and abdomen black; scape, pedicel and F-I-IV red; F-V-XI dark brown; forefemur dark brown, reddish apically, midleg, foretibia and tarsi red, hindleg all dark brown; entire body with long erect reddish setae.

Female. Same as male, except clypeus shorter; F-I 1.9-2.0 $\times$ as long as broad; F-II $0.7 \times$ as long as broad; scape, pedicel and basal half of F-I red; rest of flagellum dark brown. 
Holotype male: MALAYSIA: Pasoh Forest Res., Negri S., 17 April 1980, P. and M. Becker (GAInesville). Paratypes: 9 males, 4 females, same data as type, except differing dates, from 19 August 1978 to 29 May 1980.

\section{SUMMARY}

Three new species of Cladobethylus, 1 new Atoposega, 1 new Isegama and 3 new genera, Magdalium (cuneifacialis), Kryptosega (anomala and kaindeana) and Bupon (pasohanus), are described. Most of this material was collected in the Pasoh Forest Reserve in Malaysia. The others, including Cladobethylus aquilus and both species of Kryptosega are from New Guinea, and C. japonicus is from Japan.

\section{ACKNOWLEDGMENTS}

This study was made possible by Henry Townes, and numerous fruitful discussions of Amiseginae with Karl V. Krombein, and was supported by NSF Research Grant No. BSR-8407392. 

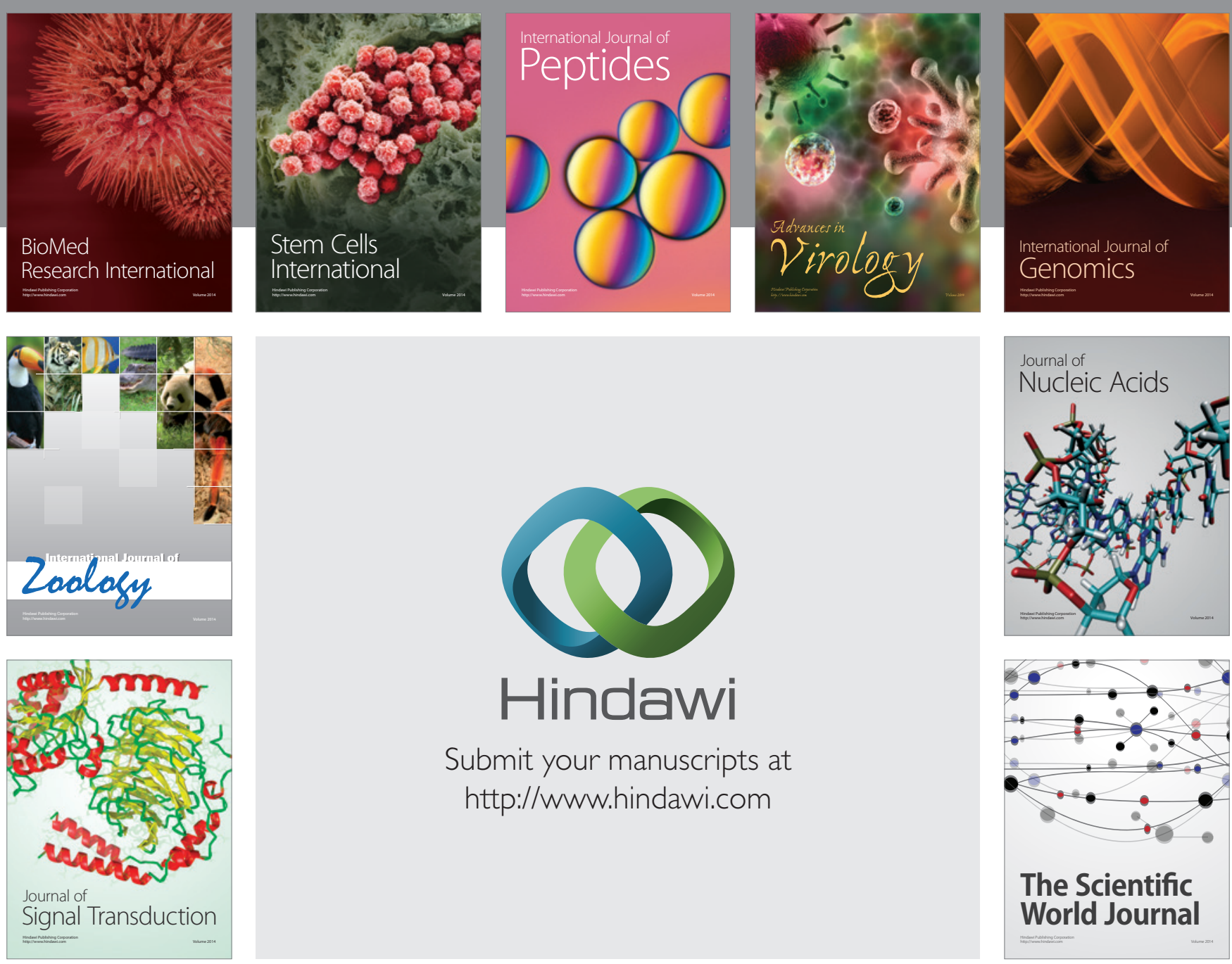

Submit your manuscripts at

http://www.hindawi.com
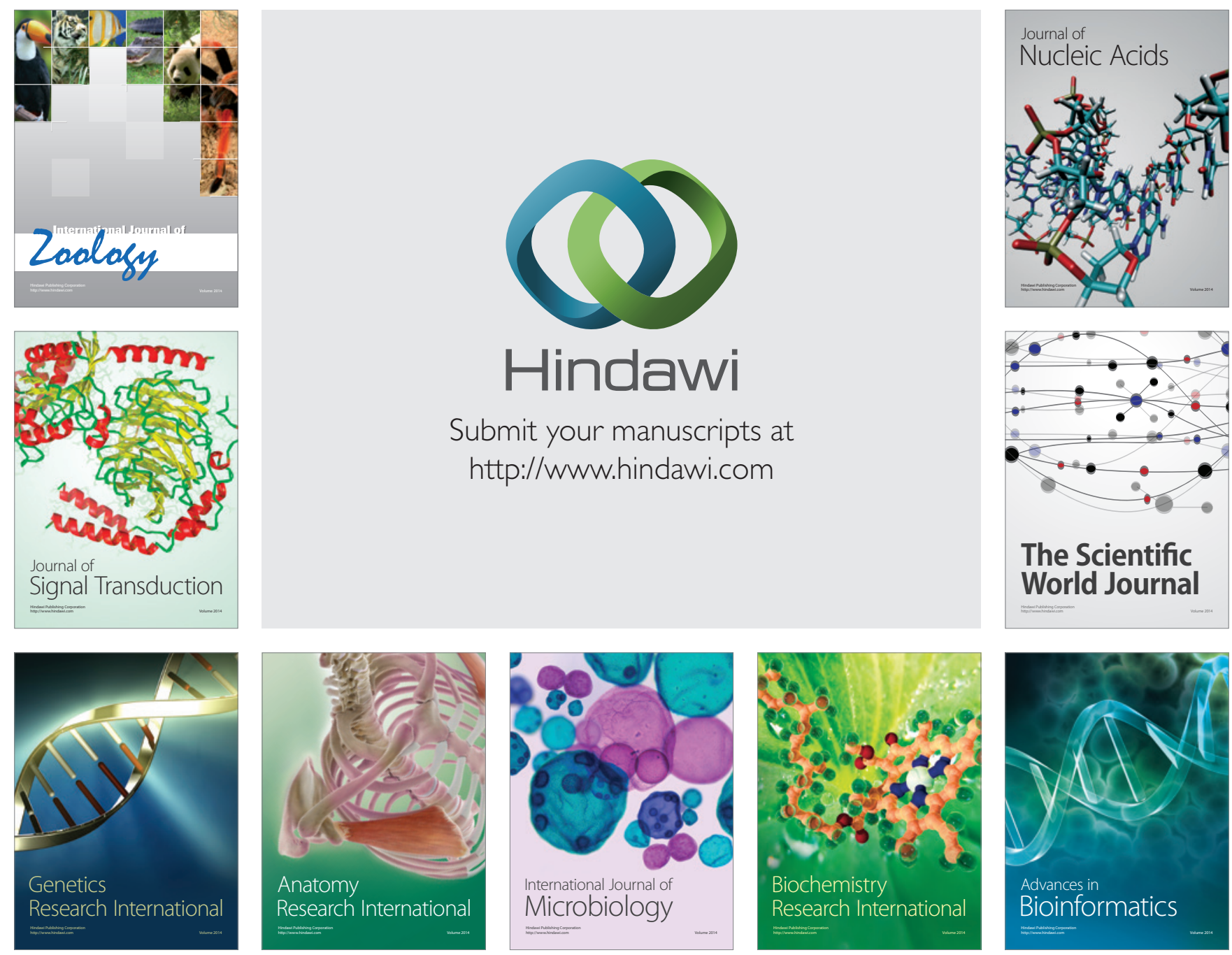

The Scientific World Journal
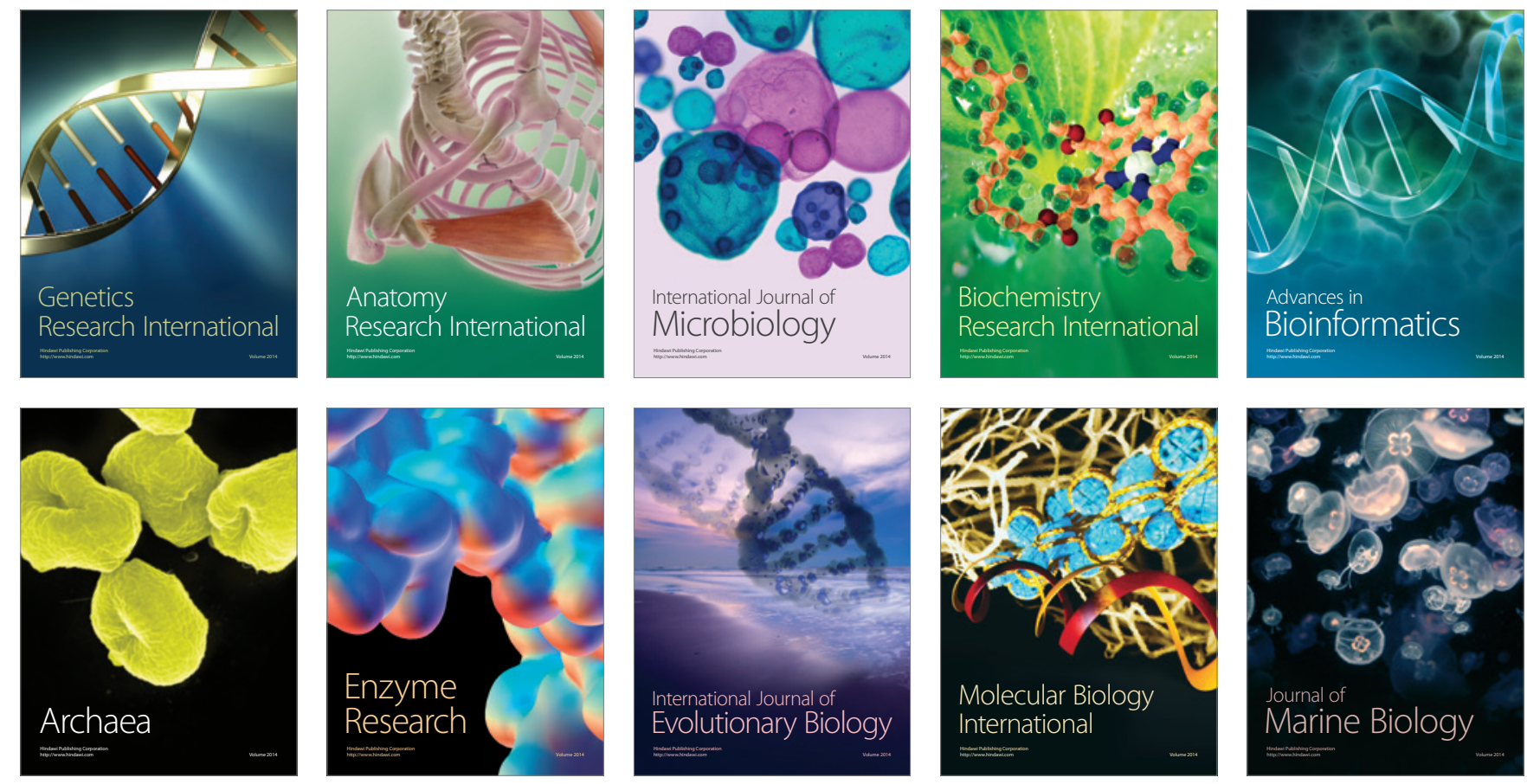